\title{
Linguistics in the Framework of Three-Dimensional Logo: Letter, Note, Numeral
}

\author{
Antipenko Leonid Grigoryevich ${ }^{1}$ \\ ${ }^{1}$ Senior Researcher, PhD RAS Institute of Philosophy, St. Goncharnaya, 12/1, 109240 Moscow, Russian Federation \\ Correspondence: Antipenko Leonid Grigoryevich, Senior Researcher, PhD RAS Institute of Philosophy, St. \\ Goncharnaya, 12/1, 109240 Moscow, Russian Federation.
}

Received: March 26, 2020

Accepted: June 28, $2020 \quad$ Online Published: July 22, 2020

doi:10.5430/wjel.v10n2p39

URL: https://doi.org/10.5430/wjel.v10n2p39

\begin{abstract}
The task of the article is return prosody to linguistics, to turn linguistics to speech, to voice content. For this, linguistics rises to the logo. It is shown that the logo as such is divided into three hypostases: the verbal logo, the musical logo (melos) and mathematical logo. The results of objectifications (Entäusserung, Gegenständlichkeit in German) of these components are expressed respectively by letters, notes and numerals. Each of the three components has two aspects that the author calls styles. The verbal logo has a prosaic and poetic style; musical logo has vocal (voice) and musical-instrumental style; mathematical logo has a logical style and a historical style.

Martin Heidegger showed that the logo is inextricable linked with time. The projection of time on the created images - verbal and poetic (letters), musical (notes), mathematical (numerals) - allows you to fill them with life, to give them a natural look.

Thus, orientation to the logos leads the linguist to a wider understanding of the subject of linguistics in comparison with the previous, narrowed version of its interpretation.
\end{abstract}

Keywords: logo, language, speech, prosody, melos, letter, note, numeral

\section{Introduction}

The goal is to redefine the subject of the linguistics from the perspective of a philosophical category logo. The ancient Greek term $\lambda$ ó $\gamma$ ○ 5 means speech, word, mind. According to the research of S. N. Trubetskoy, the ancient Greeks designated the concept of the logo as directing the rational beginning, the "single wisdom" of Heraclitus [Trubetskoi S. N., 1997, p. 149]. Because a single universal logo translates into human life, it is divided into three hypostases: the verbal logo, the music logo (melos) and the numerical logo (mathematics). None of the three types of logo can not be reduced to each of them. So, explaining the essence of the melos, K. Metner wrote that music sings of the unspeakable. For the untold, what is needed is not words, but meanings. "These meanings are in the agreed complexity of sounds. In other words: the roots of music in no way are the scattered atoms of sounds that exist in nature, and just as letters did not give rise to speech words, but from the words an letter alphabet was formed, and from musical meanings - a sound alphabet» [Metner, N. K., 1996, p . 450].

We affirm that the three types of logos - verbal, musical and numerical - exist indistinctly and inseparably. In addition, it must be borne in mind that individual modifications of one or another type of logo can very closely intertwine with another type. And verbal poetry embodiment logo that A. S. Pushkin called the divine Logos (Glagol in Russian) often comes so close to the melos that the verses themselves beg for music.

Linguistics in general terms is literature. Its element is words and their semantic connections. But to say thus is not yet to give a definition of the subject of linguistics on the merits. In a first, because it is necessary to distinguish from semiotics, or semiology,- the science of sign systems. Indeed, words can be interpreted as conventional signs by which a person is guided in his actions, in his activity. But words are not just signs. Secondly, the linguistic literature as noted above, is in contact with music, and with the mathematics. Mathematics is a tool through which the connection of linguistics with the temporal essence of the logos and with the historical genesis of the language is established.

Our version of linguistics is incompatible with such doctrines about the origin of the human language, as the doctrine of the Russian linguist Vyacheslav Ivanov. He believes that the basis for the emergence and development of the human language is gesticulation. It is as if ancient people, like anthropoids, endowed with the ability to express Published by Sciedu Press 
gestures, moved from gestures to grimaces, and grimaces gave rise to human speech [Ivanov, Vyaceslav, 2015].

\section{Research Method}

The research method is a dialectical method in the sense that it uses a metalogical operation called privation. It is borrowed here from the fundamental ontology of Martin a Heidegger (1889-1976). Heidegger enriched the concept of logos, exalting it above being (Seiende) as Being (Seyn). At the level of Being, the author has a picture of existential time, in which time can change the direction of its course - from direct to reverse. Since the transition from one direction of time to the opposite direction occurs out of time (i.e. instantly ), this allows, according to the author, to designate this transition as Nothing. And Being itself is redundant (descends) into Nothing in order to be reborn again.

Nothing is not added to Being from the outside; Nothing is presented as a lack of Being and a lack of time in time. This is the original meaning of privation, which is passed by Heidegger in the following proposition: "If we have something to deny, so that not only exclude, but rather fix in terms of shortage, such a negation is called privation (Privation)» (Heidegger, M., 2022, p. 86). In Boolean algebra of classical logic and in the mathematical theory of sets, a characteristic and partly the result of privation is an empty class or an empty set.

In the doctrine of versification (meter, foot, caesura, rhythm), nothing takes place caesura.

Andrew Tavrov, orthodox Christian philosopher, points to the example of thinking, which employs caesura. Homer's Odyssey, he notes, is written with a hexameter - a verse that must certainly have two pauses - in the middle of the line, on the second or third foot, and at the end where the line ends. Why is caesura needed, this pause, a moment of silence among the stream of words? - he asks. And he answers: "So that among the words God may be present . <... >. Silence, not only and not so much takes places about among words-objects, how many these words-objects forms, creates. ... Without a divine pause there would be no Odyssey "[Tavrov, A., 2010, p . 143].

Below we will try to get to know these issues more closely.

\section{The Prosaic and Artistic and Poetic Style of the Verbal Logo}

One of the most significant attempts to determine the difference between the one and the other style of the verbal logo belongs to our compatriot A. A. Potebnya (1835-1891). The starting point of the teaching of Potebnya is the provision on sensory perception, which is marked with a word, and the provision on representation, to be more precise, the representative feature chosen from this sensory perception. So we take, for example, a word and see that in the vocabulary this word has a certain meaning, revealed and explained by a number of other words. The word, says Potebnya, is a psychological association of a sound complex with a certain meaning. The content fixed by the word, Potebnya calls the external form of the word. But besides this external form, the word also has an internal form. The inner form is the closest etymological meaning of the word. For example, when we pronounce words such as "snowdrop", "bear", «protection», they show signs, each taken from one of the general perceptions, indicating why this subject is called by such and not another word. In the word "defense" we have an echo of the shield with which the ancient warrior defended himself from the spear and arrows of the enemy. The fact that a word that has not acquired the status of a logical concept has a figurative content, hardly anyone can doubt.

Prose, indicates Potebnya, is generated when the loss of the poetry of a word occurs as a result of the transformation of a sensory image into a concept. "But no matter how abstract and deep," he writes, "our thought has not reached, it does not get rid of the need to return, as it were, to refresh to its starting point. Language is not only the material of poetry, like marble -sculpting, but poetry itself, and yet poetry in it is impossible if the visual meaning of the word is forgotten" [Potebnya, A. A., 1922, p.169-170]. The term "presentation" should not be misleading, it should not be, we note again, confused with sensory perception. Representation for Potebnya has a characteristic feature ("cow" = "horny"), and as a sign it was about an abstraction, along with those abstractions in which concepts are formed. So it is from these representative abstraction features that the artistic image is obtained. From this point of view, any poetic image or artistic type is nothing more than an abstraction-idealization, idealization in the sense that, as Potebnya believes, it means the possibility of the transition of the lower layers of our mental life to the higher.

However, it is not entirely clear how the opportunity indicated by the author is realized. For, in order to clarify this judgment, he says that the idealization of the artistic type consists, again, in isolating some significant features from the main complex of perceptions, in eliminating others, the presence of which would lead the mind astray. Therefore, in science and in art, the same daunting task is solved, albeit by different means (different in the sense of species attributes of abstraction as such): to transfer all nature to the country of ideas, i.e. to compare the content of experience with the world in volume. The ultimate goal of a person's mental efforts is "to combine this huge mass of fragmentary phenomena into inseparable unity and organized wholeness" [Potebnya, A. A., 1922, p. 154-155]. 
If the image is formed only from below, is formed by abstractions, it is not clear how the image can direct the process of abstraction leading to this image. Potebnya here, apparently, falls into a mistake called petitio principii, although this does not detract from his merits in discovering the internal form of the word.

Below we will indicate the possibility of avoiding petitio principii in this case.

\section{The Logical and Historical Style of the Numerical Logo}

Now we turn to the numerical universe (as is commonly expressed in modern mathematics) and to its central concept of the natural series of numbers. In a natural series of numbers, positive integers perform different functions, depending on whether it is considered in one of two perspectives - direct or inverse - or combines both of these alternatives. When this numerical sequence was as explicated and by induction with all the properties of numbers computed inductive same method (recursive computation), it was found its incompleteness (Gödel incompleteness theorems). It turned out that there is a split of numbers in such a way that some numbers are "directed towards the past", others "towards the future" without observing the symmetry of one or the other direction. This numerical antinomism is explained by the paradoxical nature of this numerical sequence. On the one hand, it does not have the last member; on the other hand, it is considered to be actually given (by all its elements) and is estimated by an ordinal number $\omega$.

How did this mysterious system originate and who was the first thinker who invented or discovered it? According to legend, this merit belongs to the titan Prometheus. In the tragedy of the ancient Greek playwright Aeschylus "Chained Prometheus", the following confession of the suffering God-wrestler (punished by Zeus for stealing fire from Olympic celestials and brought as a gift to people) is described:

Yes, and numbers, too, chiefest of sciences,

I invented for them, and the combining of letters,

Creative mother of the Muses' arts,

With which to hold all things in memory.

To keep all things in mind, one must have a biographical and tribal memory.

Let's see how it looks in a mathematical representation.

As you know, every mathematician, with the possible exception of ultraconstructivists, recognizes the existence of a (countable) sequence of natural numbers, terminated by an infinite ordinal number:

$$
1,2,3, \ldots, n, \ldots \omega
$$

Hence the principle of mathematical induction, i.e. the principle of generating natural numbers and determining their (inductive) properties. Here, however, a paradoxical question arises: how does it turn out that mathematicians combine seemingly incompatible provisions: the idea that sequence (1) does not have the last term and the idea of it as an actual given infinity. It is possible to resolve this contradiction just when becoming acquainted with the ancient Greek legend of Prometheus.

As you can see, the biographical memory and the genetic (generic) memory of Prometheus correlates with numbers, fixing it with "compound letters". Consequently, we are talking about calculating the years going back centuries to the extent that it is customary to note in the Slavic-Russian language with the words "during the ono". form:

In the light of the Promethean mind (Promethean fire), you should wrap the sequence (1) and present it in the

$$
\omega \ldots, n, n-1, \ldots, 1,0
$$

where 0 becomes the mark of the moment «now», from which the countdown goes back centuries (following the example of the Tale of Bygone Years). It is now clear how the natural series of numbers turns into actual infinity, if we keep in mind that this series retrospectively looks like it has already taken place. After all, his numerical evaluation, presented by the ordinal $\omega$, cannot be changed, no matter how long the movement continues along the course of time into the future. In this case, if sequence (1) serves as an expression of time perspective, then sequence (2) serves as an expression of temporary retrospective. We are dealing with the combination of two oppositions.

The Promethean contemplation of the reverse passage of time (from memory), represented by this numerical model, was reflected not only in the tragedy of Aeschylus. We find it in particular, at William Shakespeare, in his 104 sonnet:

Ah yet doth beauty, like a dial-hand, 
Steal from his figure, and no pace perceived;

So your sweet hue, which methinks still doth stand,

Hath motion, and mine eye may be deceived;

For fear of which, hear this, thou age unbred:

Ere you were born beauty's summer dead.

In the Russian version, the last three verses are conveyed in the following words:

So I don't notice on you for years. / And if sunset is necessary,-/ It was before your birth.

Prometheus' contemplation of a natural row of numbers in modern mathematics allows to return its temporal content. This is the replenishment of the very deficiency that is established in the Gödel incompleteness theorems.

And finally, the logical in mathematics means a spatially similar (spacelike) disposition of mathematical systems and structures, which is abstracted from time. That is where classical formal logic stands. The historical in mathematics restores in it the ontological right of time. So, the non-Euclidean geometry of Lobachevsky arose as a result of the fact that the Euclidean geometry was re-immersed in (historical) time and was subject to privation. Privation allows the synthesis of the logical and the historical in mathematics.

\section{Caesura and the Doctrine of Versification}

Since the next topic on the song and musical-instrumental style is not directly related to literature, we will postpone its analysis for the future. And here we return to the issue of caesura in the framework of the doctrine of versification. To do this, we turn to Valery Bryusov's book "A Short Course on the Science of Poem".

Caesura (lat. Caesura -cut, division) is, according to Bryusov, a break of the verse, dividing it into parts. (A verse is considered in advance as metric, therefore the author sometimes puts the word "meter" in place of the word "verse"). At the end of each verse, or meter, a natural caesura is assumed. Caesuras are distinguished: large, which is represented by the // sign, and small, which is represented by the / sign. When there is no need to distinguish between small caesuras, a large caesura can also be represented by the sign [Bryusov, Valery, 1919, p. 18]. The verse, in turn, is an element of rhythmic speech. The basis of the rhythm of the verse is its meter, metricity, although it may be, Bryusov points out, are not rhythmic verses that are of no interest to us here.

The exact definition of the meter: meter is a combination of a stop in a certain sequence (p. 15). A stop in a tonic versification is a combination, in a certain sequence, of stressed and unstressed syllables. By the number of syllables, the feet are monosyllabic; two-syllable, or simple; three-complex; four- membered, or diapodia; five-syllable [Bryusov, Valery, 1919, p. 12].

Further, the author notes that, as shown by comparative poetry, the following systems of versification exist:

1. metric (in the narrow sense of the term) system based on a combination of long and short syllables (it was used by the ancient Greeks and Romans);

2. tonic based on a combination of stressed and unstressed syllables and adopted by the British German, Russian, and others.

3. sillabic based on the number of syllables in verse and accepted by the French, Italian, Spanish, Poles etc. [Bryusov, Valery, 1919, p. 7].

There are other, exotic, versification systems mentioned by Bryusov that are not interesting for us in this context. In Russian poetry, since the time of Lomonosov, a tonic system has been adopted, which is taken as a sample of our reasoning.

Bryusov considers the concepts of meter, rhythm, foot, caesura in the doctrine of versification from a purely technical point of view. Our attention is riveted to them to a greater extent because they provide an opportunity to raise literature to the level of an ideally semantic world, to the world of ideas or eidos of Plato, who introduced privation into the philosophical discourse. A fairly qualified analysis of the Platonic dialogue «Timaeus», made by N. I. Grigoryeva, will help me to highlight the meaningful connection between privation and caesura [Grigoryeva, N. I., 1981].

In the debate of the Timaeus dialogue, Socrates, Timaeus, Critius, and Hermocrates participate. At the end of the discussion Timaeus delivers a monologue which is commented by Grigoryeva. In the most cursory reading of Timaeus' monologue, she writes, we notice a clear division into two large parts with the conditional names "Demiurge" and "Matter" (p. 51). In these parts, respectively, two intelligible reasons for the birth of the cosmos are mentioned: "Demiurge "- divine, "Matter» - necessary. So, she continues her comment, most people who are more or less familiar 
with the contents of Timaeus believe that the Demiurge, creating the Universe, will transform some source material. In fact, this second reason is neither matter nor material, i.e. there is not something that can be built. "We are talking about an object that has neither an image, nor a concept, nor even a symbol. Objectively (for Demiurge) it is "something", but this "not what" for the consciousness of a living (embodied) being is covered in complete darkness. It is "nothing" for him. It can only be something for the Organizer" [Grigoryeva, N. I. 1981, p. 64].

As a result, Plato with the Timaues' mouth expresses the dreamy nature: what "something" might comprehend just being like in a dream, and awake, we shall not be able to call it ( $\lambda$ éyeív) (52c.). And only some unfamiliar calculus

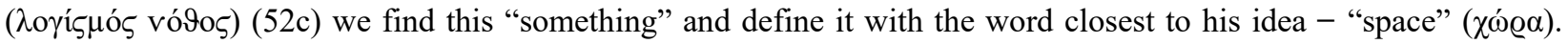
"However ( $\chi \omega \hat{\varrho} \alpha$ ) in this context means "space" not in the sense of its modern understanding. If we take into account

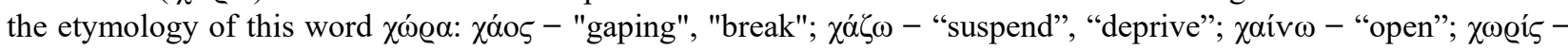

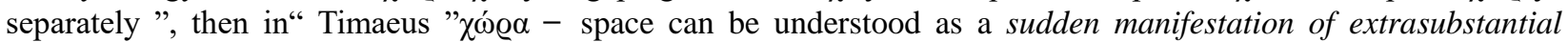
extension generated by the transcendent coming out of the self- pressure state or by the process of its polarization inside itself" [Grigoryeva N. I., 1981, p. 64-65].

Here it is correctly noted about the "polarization within oneself," because in another Plato dialogue "Sophist" we find the operation of self-negation of Being with the transformation of Being just into "nothing." In Heidegger, Nothing do not correlate, however, with the image of a spatial gap, but with the self-denial of Being and with the reversal of time. In the lumen of Heidegger's Being there appears a human literature along with a caesura, evident in an artistic-poetic speech.

\section{Criticism of the Postmodern Interpretation of Linguistics}

In postmodernism, linguistics began to be considered as one of the branches of semiology. The forerunner of postmodernism in linguistic issues was the Swiss psychoanalyst Ferdinand de Saussure (1857-1913). According to information about him he laid the foundations of semiology and structural linguistics and was the founder of the Geneva Linguistic School. Semiology has been designated as a science that studies "the life of signs within the framework of society." It should have revealed to us why signs are needed, what laws govern their functioning. De Saussure argued that semiology should be part of social psychology; determining its place in social psychology is the task of a psychologist. The task of the linguist is to find out what distinguishes language as a special system of semiological phenomena. Since language is one of the systems of signs, linguistics is part of semiology. It is believed, and so de Saussure himself believed, that he accomplished a kind of "Copernican coup" in linguistics.

In the context of our subjects, it will be interesting to see what this «Copernican coup» consists of.

Our definition of the linguistic sign, writes de Saussure, poses an important question of terminology. He calls the combination of a concept and sound-image a sign, although in current usage the term generally designates only a sound-image, a word, for example (arbor, etc.). One tends to forget that arbor is called a sign only because it carries the concept «tree», with the result that the idea of sensory part implies the idea of the whole [Saussure, F. de, 1959]. P. 67].

And so ambiguity would disappear if the three notions involved here were designated by three names, each suggesting and opposing the others. «I propose», indicates Saussure, «to retain the word sign [signe] to designate the whole and to replace concept and sound-image respectively by signified [signifié] and signifier [signifiant]; the last two terms have advantage of indicating the opposition that separates them from each other and from the whole of which the are parts. As regards sign, if I am satisfied with it, this is simply because I do not how of any word to replace it, the ordinary language suggesting no other» $\langle\ldots\rangle$.

The two principles formulated by de Saussure in the framework of semiology testify that it passes by scientifically significant linguistics. Here's what they look like in de Saussure's literal wording.

\section{«Principle I: The Arbitrary Nature of the Sign}

The bond between the signifier and signified is arbitrary. Since I mean by sign the whole that results from the associating of the signifier with the signified, I can simply say: linguistic sign is arbitrary» [Saussure, F. de, 1959, p. 67].

\section{«Principle II: The Linear Nature of the Signifier}

The signifier, being auditory, is unfolded solely in time from which is gets the following characteristics: (a) it represents a span, and (b) the span is measurable in a single dimension; it is a line.

While Principle II is obvious, apparently linguists have always neglected to state it, doubtless because they found it too simple; nevertheless, it is fundamental, and its consequences are incalculable. Its importance equals that of Principle I...» [ Saussure, F. de, 1959, p. 70]. 
What can I say? De Saussure's assertion that the connection between the signifier and the signified is completely arbitrary stems from the fact that in linguistics he does not feel the associations between words in utterances. In addition, and this is important, for him does not exist in the statements of what we call prosody. He deals with mechanically leveled time, along the line of which he arranges the sound of a word. In general, the poetry of words is absent for him.

Nevertheless, it makes sense to get acquainted with de Saussure's «Copernican coup», since he laid the foundation for postmodernist ideology in the doctrine of language and other branches of knowledge.

So, postmodernist ideology was born as such in the sphere (interpretation) of linguistic phenomena. However, then it went beyond these limits and encompassed all other areas of social reality, including the economic life of society, studied by political economy. As A. S. Panarin notes, postmodernists (F. de Saussure, J. Derrida and others) fill the Marxist concept of the total value of goods with semiotic content. If the universal form of value at Karl Marx meant the ability of a given product to be exchanged for any product regardless of natural, material differences, "then the universal semiotic form of value means the exchange of any reality for a sign and the ability of the latter to completely supplant reality" [Panarin, A. S., 2014].

The arguments of J. Derrida (1930-2004) regarding linguistics do not concern so much the value of goods, but rather money. He designates his "grammatology" as the movement of analytical abstraction in the circulation of arbitrary signs parallel to the movement of money. Money replaces things with signs of things. Moreover, not only within the given society, but also in relations between cultures, between economic organisms. That is why the alphabet is a commercial matter. It must be understood within the monetary system of economic rationality. A critical description of money is, at the same time, a faithful depiction of thoughts about writing. In both of these cases, the thing is replaced by some faceless replenishment. "As a concept,-Derrida writes - retains only what different things available over how money gives disparate things their "common measure ", turning them into commodities, as well, and a literal translation of the letter in an arbitrary and general meaning heterogeneous signified - living languages. Thus, it threatens life, which it sets in motion " [Derrida, J., 1967].

Not all human culture, let us say, is amenable to commercialization. Take, for example, the song gift of man! It, like any heavenly gift, has the property of non-selling. In general, it is impossible to digitize. .

\section{Conclusion}

Summaring up the above considerations, we note the following. Phenomenologically in the language we distinguish, in any case, two components:

1) the component related to the economic way of life of people (all kinds of notes and receipts related to the list of items, debt obligations, etc.), without which we cannot imagine, say, material exchange in the human community (prose, and only);

2) the prosodic component, which includes a song, a hymn, a call, an appeal to what rises above utilitarian-economic needs.

The second component serves as a means of connecting the prose language with logo, because it is connected, in turn, with melos. Thus arose the idea of two-dimensional logo with verbal and music hypostases. The third hypostasis in our presentation is mathematics. Previously, mathematics was simply enrolled in the department of prose. This can be explained by the fact that they did not catch the rooted logos in the temporary element. And this rootedness is written about only in the language of mathematics, which was shown in Heidegger's fundamental ontology. This is how the third hypostasis of the logo manifested itself. The subject of linguistics has received a broader interpretation.

The language as a whole, according to Heidegger, is thought-remembered as the language of Being, the silent language of stillness (remember ceasura) [Biemel, 1973, p. 254]. It allows the opposing world regions to remain together and at the same time in mutual opposition. But language is speech and how it sounds. "The voice of speech is not understood as the result of physiological and physical processes. The sounding ... of speech is held in the announcement, which, hiding the opposite regions of the universe, harmonizes them with each other " [Biemel, 1973, p .207 - 208].

The relationship between opposite regions of the universe is a relationship that satisfies the principle of N. Bohr: contraria sunt complementa.

\section{Acnowledgemens}

I grace the editorial board of English Language, Literature and Culture Magazin for publishing my article (Antipenko, L. G. 2019). 


\section{References}

Antipenko, L. G. (2019). Natural Science Value of Linguistics in Historical research. English Language, Literature \& Culture, 4(4), 93-98. https://doi.org/10.11648/j.ell.20190404.12

Bryusov, V. (1919). Kratkii kurs nauki o stikhe. Chast pervaya. Osnovy russkoi metriki (Chastnaya metrika i ritmika russkogo yazyka). Moscow, « $\mathrm{Al}$ 'tsiona », 1919.

Derrida, Z. (1967). O grammatologii. (Derrida, Jacques. About grammatology). [Elektronnyi resurs] Retrieved from http://www.opentextnn. com/man/?id=3849

Grigoryeva, N. I. (1981). Paradoksy platonovckogo "Timeya": dialog i gimn // Poetika drevnegrecheskoi literatury. Moscow: « Nauka », 1981.

Heidegger, M. (2012). Tsollikonovskie seminary. Vilnyus: Evropeiskii universitet, 2012.

Ivanov, Vyacheslav. Vselennaya smotrit na sebya glazami lyudei. Istochnik. Retrieved from https://subscribe.ru/group/pole-chudes/8537284

Martin Heidegger sam o sebe v izlozhenii Val'tera Bimelya (per. s nemetskogo). Ural LTD, 1998. (Martin Heidegger mit Selbstzeugnissen und Bilddokumenten dargestell $t$ von Walter Biemel. Rowohlt, 1973).

Metner, N. K. Muza i moda / Il 'in I. A. Sobr. soch. v 10 t .: t. 6. Kn.1. M .: "Russkaya kniga", 1996. S. 445-533

Panarin, A. S. (2014). Trudnoe vozvrashchenie $k$ bytiyu // Pravoslavnaya tsivilizatsiya v global'nom mire. Glava: Dobro i zlo. M.: Institut russkoi tsivilizatsii, 2014. (Panarin A. S. Difficult return to being / Orthodox civilization in global world. Glapter: Good and evil). [Elektronnyi resurs] Retrieved from wordweb.com/panarin/20.htm

Potebnya, A. A. (1922). Mysl' i yazyk. Odessa, 1922 (4th ed.). (Potebnaya A. A. Thought and language. Odessa, 1922.

Saussure, F. D. (1959). Course in General Linguistics. Edit by Charles Bally and Albert Sechehaye. Philosophical Library. New York, 1959.

Tavrov, A. (2010). Smena paradigm-ob'ekty ili tsezyra? (Perspektivy Khristianskoi filosofii v Rossii. Mezhdunarodnyi filosofskii seminar). Moscow, 31 maya 2010 goda. (S. 142-149).

Trubetskoi, S. N. (1997). Kurs istorii drevnei filosofii. M .: Gumanit. izd. tsentr VLADOS; Russkii Dvor, 1997. (Trubetskoy S. N. Course in the history of ancient philosophy. M .: Humanity. ed. VLADOS center; Russian Court, 1997).

\section{Copyrights}

Copyright for this article is retained by the author(s), with first publication rights granted to the journal.

This is an open-access article distributed under the terms and conditions of the Creative Commons Attribution license (http://creativecommons.org/licenses/by/4.0/). 